Maria Barnai · Istvan Laki · Kalman Gyurkovits

Lajos Angyan · Gyöngyi Horvath

\title{
Relationship between breath-hold time and physical performance in patients with cystic fibrosis
}

Received: 6 October 2004 / Accepted: 8 March 2004/Published online: 9 July 2005

(C) Springer-Verlag 2005

\begin{abstract}
Rehabilitation including physiotherapy is an important part of the treatment used to help improve the quality of life of patients with cystic fibrosis (CF). The aim of this study was to determine the value of the breath-hold time as an index of exercise tolerance in patients with CF. Eighteen patients in different states of $\mathrm{CF}$ were included. The breath-hold time was measured in all patients. The fitness level was assessed by means of a progressive exercise test on a cycle-ergometer. During the test, oxygen uptake $\left(V \mathrm{O}_{2}\right)$ and carbon dioxide elimination $\left(V \mathrm{CO}_{2}\right)$ were measured breath by breath. The $V \mathrm{O}_{2}$ and working capacity (WC) were computed at the anaerobic threshold (AT) and at peak.
\end{abstract}

The institutional review board was the Human Ethics Committee of The Hospital of Chest Diseases of the Protestant Church of Hungary, Mosdós. The rights of human subjects were fully protected.

M. Barnai $(\bowtie) \cdot$ G. Horvath

Department of Physiotherapy,

Faculty of Health Science,

University of Szeged, Temesvari Krt. 31,

6726 Szeged, Hungary

E-mail: barnai@efk.u-szeged.hu

Tel.: + 36-62-545037

Fax: + 36-62-545037

I. Laki

Somogy County Hospital, Kaposvár, Hungary

K. Gyurkovits

Hospital of Chest Diseases of the

Protestant Church of Hungary,

Mosdós, Hungary

L. Angyan

Institute of Human Movement Sciences,

Medical School,

University of Pécs, Hungary

G. Horvath

Department of Physiology, Faculty of Medicine,

University of Szeged, Szeged, Hungary
Duration of breath-hold was $24.7 \pm 2.87$ (mean \pm SEM) seconds, varying between 10 and 58. The breathhold time (BHT) displayed a significant correlation with $V \mathrm{O}_{2}(r=0.898)$, WC $(r=0.899)$ at the AT, and the peak $V \mathrm{O}_{2}(r=0.895)$. Regression equations were: $V \mathrm{O}_{2}$ at the AT $(\mathrm{ml} / \mathrm{kg})=5.53+0.42 \times \mathrm{BHT}$ and $\mathrm{WC}$ at the AT $($ watt $/ \mathrm{kg})=0.56+0.38 \times \mathrm{BHT}$ Our results suggest that the voluntary breath-hold time might be a useful index for prediction of the exercise tolerance of $\mathrm{CF}$ patients.

Keywords Anaerobic threshold (AT) - Lung disease · Oxygen uptake $\left(V \mathrm{O}_{2}\right) \cdot$ Working capacity (WC)

\section{Introduction}

Cystic fibrosis (CF) is the most common fatal autosomal recessive genetically inherited disease among white populations (Gibson et al. 2003). CF alters the ability of the epithelial cells to secrete mucus. The secreted mucus is much thicker and stickier than normal. The decreased mucociliary transport in $\mathrm{CF}$ is accompanied by mucus retention, which causes airway obstruction, recurrent infections and finally destruction of the lung tissues, i.e., emphysema and fibrosis. Therefore, healthy respiratory surface becomes progressively smaller, and the pulmonary artery capacity decreases.

The quality of life of CF patients is mainly related to their pulmonary status and physical condition. The cardiopulmonary status may change within a short time, and the physical activity must therefore be adapted to the changes. Appropriate, regular exercise is of benefit to patient with cystic fibrosis (Prasad and Cerny 2002). Thus, as shown by Selvadurai et al. (2002), the aerobic training increased the aerobic capacity, activity levels and quality of life. Other demonstrable benefits of aerobic exercise in $\mathrm{CF}$ 
patients include decreased dyspnoea, improved mucociliary clearance (O'Neill et al. 1987; Baldwin et al. 1994). Furthermore, it is well known that the exercise intensity prescriptions used for healthy adults are not appropriate for the $\mathrm{CF}$ population (Freeman et al. 1993). The anaerobic threshold (AT) and the maximal oxygen uptake $\left(V \mathrm{O}_{2}\right)$ is a submaximal/maximal index of aerobic fitness that is closely related to endurance performance. An accurate method for determination of the AT is the progressive exercise test on a cycle ergometer or treadmill based either on the increase of the lactic acid level in the blood, or on the steep rise in carbon dioxide $\left(V \mathrm{CO}_{2}\right)$ production in the exhaled air. A steep rise in $\mathrm{CO}_{2}$ elimination exceeding the degree of rise in $\mathrm{O}_{2}$ uptake indicates the compensatory mechanism of lactacidosis as shown by Casaburi (1993). Hence, the respiratory exchange rate (RE$\mathrm{R})=V \mathrm{CO}_{2} / V \mathrm{O}_{2}$ may also be used to determine the AT (Dickstein et al. 1990). During a progressive exercise test, the training pulse and workload at the AT are measured exactly. These values allow determination of the level of the training activity. However, exact determination of these parameters during an exercise test requires continuous measurement of $\mathrm{CO}_{2}$ output and $\mathrm{O}_{2}$ input with suitable instruments, special software and well-trained assistance. In order to monitor responses to training programs and to investigate the mechanisms by which aerobic exercise exerts its beneficial effects, simple methods of quantifying aerobic fitness in patients with $\mathrm{CF}$ are required that are not excessively stressful and are readily acceptable to patients.

The breakpoint of a voluntary breath-hold occurs when the urge to resume breathing exceeds the will to hold the breath. Breath-holding time (BHT) has been used in respiratory physiology as a measure of ventilatory response in study of Godfrey and Campbell (1986). It is well known that the breath-hold time depends on a number of interacting variables, which include mechanical factors (lung volumes), chemical factors (hypoxia and hypercapnia), nonchemical factors (involuntary muscular contractions), psychological factors (motivation, stress, competition) and various extrinsic factors (training and muscular exercise) (Lin et al. 1974; Whitelaw et al. 1981; Stroud 1959; Hurewitz et al 1987; Ferretti 2001; Fowler 1954; Cain 1957; Courteix et al. 1993). Most studies have been performed on divers (Ferretti 2001; Courteix et al. 1993; Delapille et al. 2001, 2002), and only a few studies investigated the voluntary breath-holding time in patients. It has been shown by Taskar et al. (1995) that BHT significantly decreased in obstructive sleep apnoea syndrome, and in obese patients by Hurewitz et al. (1987). Gay et al. (1994) observed that the BHT was decreased significantly in patients with chronic obstructive pulmonary disease, and suggested the significance of BHT determination in pulmonary diseases. Furthermore, Perez-Padilla et al. (1989) have shown that BHT correlated well with $\mathrm{FEV}_{1}$ and with the magnitude of dyspnoea in asthmatic patients. These studies indicate that the BHT might be a predicting factor in patients with different respiratory abnormalities. However, no information is available on the BHT in patients with CF. Accordingly, the aim of this study was to determine the correlation between the physical performance and the voluntary BHT in patients with CF. The possible close correlation between the BHT and $\mathrm{O}_{2}$ consumption or working capacity at AT might give a new, simple way for the prediction of the suitable training program in these patients.

\section{Methods}

\section{Subjects}

Eighteen CF patients with different levels of pulmonary dysfunction were enrolled in the study. Patients with $\mathrm{CF}$ diagnosed on the basis of clinical history and abnormal sweat electrolyte measurements were recruited from the Hospital of Chest Diseases of the Protestant Church of Hungary, Mosdós. All patients were free of acute pulmonary exacerbations for at least 1 month. The criteria for inclusion were a stable physical condition and cooperative behavior. Exclusion criteria included young age (younger than 15 year) and acute infection and exacerbation. The study was completed on 12 women and 6 men. The subjects were patients in the Mosdós Hospital. All subjects participated in the examinations voluntarily, with written informed consent. The Ethics Committee of the Hospital of Chest Diseases of the Protestant Church of Hungary, Mosdós approved the study.

\section{Breath-hold time determination}

The subject was told to sit comfortably on a chair, and breath normally. After $1 \mathrm{~min}$, he/she was required to make a maximum expiration followed by a maximum inspiration and to hold the breath as long as possible at maximum inspiratory level by using nose clips. This procedure was repeated three times, with 5-min intervals between the trials. There were no significant differences between the trials $(P=0.985)$. The best value was used for further analysis.

\section{The physical performance testing procedure}

The current level of fitness was assessed by progressive exercise testing on a cycle ergometer (Medical Graphics CPX system). The equipment comprised a personal computer, a cycle ergometer, an electrocardiograph, a pneumotach unit and a gas analyzer. The subjects were instructed to maintain a pedaling 
cadence between 60 and 70 revolutions per min. After an initial period of 2 min without any resistance to the pedals, the workload was continuously increased at $10 \mathrm{watt} / \mathrm{min}$, as long as the patient was able to maintain the pedaling cadence. During exercise $V \mathrm{O}_{2}(\mathrm{ml} / \mathrm{kg} / \mathrm{min})$ and $V \mathrm{CO}_{2}(\mathrm{ml} / \mathrm{kg} / \mathrm{min})$ were measured breath by breath, the ventilation rate $\left(V_{E} 1 / \mathrm{min}\right)$, heart rate (HR, beats $/ \mathrm{min}$ ) and workload (watt $/ \mathrm{kg}$ ) were registered. RER was calculated as $V \mathrm{CO}_{2} / V \mathrm{O}_{2} . V \mathrm{O}_{2}$ and the working capacity (WC) at the AT were established, as were their peak values (peak $V \mathrm{O}_{2}$ and peakWC). The AT was determined as the point at which $V \mathrm{CO}_{2}=V \mathrm{O}_{2} \quad\left(\mathrm{RER}=V \mathrm{CO}_{2} / V \mathrm{O}_{2}=1\right)$, since a respiratory exchange ratio equal to 1 provides a reproducible index of submaximal cardiopulmonary exercise performance (Wisen and Wohlfart 2004). According to Dickstein et al. (1993), the RER =1 method showed substantially better correlation with peak $V \mathrm{O}_{2}$ than the gas exchange anaerobic threshold, where the rate of $V \mathrm{CO}_{2}$ increase just exceeds the rate of $V \mathrm{O}_{2}$ increase. Furthermore, the method of taking AT as the point at which $\mathrm{RER}=1$ has specific utility in patients with cardio-respiratory limitation. Peak work rate was taken as the highest value achieved during the test. Peak $V \mathrm{O}_{2}$ was calculated as the average of the $30 \mathrm{~s}$ breath-by-breath data immediately prior to the peak workload.

\section{Statistical analysis}

Data are presented as mean $\pm \mathrm{SD}$. The relationships of BHT with different parameters were assessed by linear regression analysis and calculation of Pearson correlation coefficients using STATISTICA software. A $P$ value of $<0.05$ was considered significant.

\section{Results}

The data on the 18 subjects who completed the cycle ergometer test are given in Table 1. The subjects ranged in age from 15 years to 31 years (mean $19.7 \pm 3.54$ year). Their body weight was from $38 \mathrm{~kg}$ to $59 \mathrm{~kg}$ (mean $47.3 \pm 5.96 \mathrm{~kg}$ ), which is significantly lower than the normal population. $V \mathrm{O}_{2}$ at the AT, WC at AT and BHT varied widely among the patients (Table 1). These data reflect the different conditions of the patients. Body weight did not correlate significantly with BHT, $V \mathrm{O}_{2}$ or WC. However, there were inverse correlations between the age and $\mathrm{BHT}, V \mathrm{O}_{2}, \mathrm{WC}$,

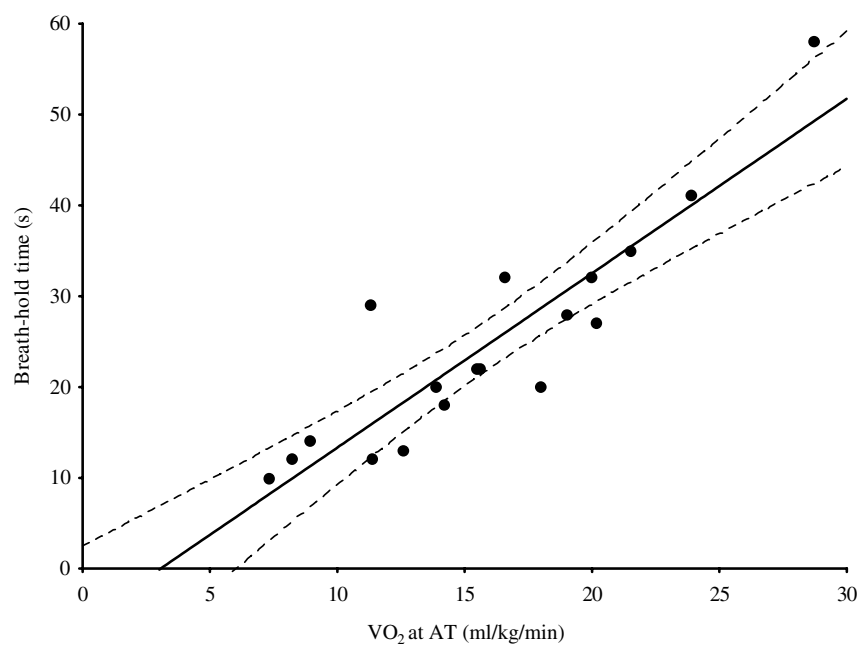

Fig. 1 Correlation between the oxygen consumption $\left(V \mathrm{O}_{2}\right)$ at anaerobic threshold (AT) and breath-hold time (BHT). The regression analysis indicated a significant relationship between two data $(r=0.898)$

Table 1 Summary of anthropometric and physiological data

\begin{tabular}{|c|c|c|c|c|c|c|c|}
\hline No. & Body weight (kg) & Age (years) & $\mathrm{BHT}(\mathrm{s})$ & $V \mathrm{O}_{2}$ at $\mathrm{AT}(\mathrm{ml} / \mathrm{kg} / \mathrm{min})$ & Peak $V \mathrm{O}_{2}(\mathrm{ml} / \mathrm{kg} / \mathrm{min})$ & WC at AT (watt $/ \mathrm{kg}$ ) & PeakWC (watt/kg) \\
\hline $1^{*}$ & 45 & 23 & 10 & 7.3 & 9.7 & 0.8 & 1.15 \\
\hline 2 & 51 & 31 & 12 & 8.2 & 11.1 & 0.7 & 1.6 \\
\hline 3 & 41 & 22 & 12 & 11.4 & 12.2 & 1.0 & 1.15 \\
\hline 4 & 53 & 22 & 13 & 12.6 & 14.6 & 1.1 & 2.17 \\
\hline 5 & 59 & 18 & 14 & 8.9 & 27.5 & 0.9 & 2.5 \\
\hline 6 & 38 & 18 & 18 & 14.2 & 17.7 & 1.5 & 2.0 \\
\hline 7 & 43 & 19 & 20 & 13.9 & 20.5 & 1.2 & 2.4 \\
\hline 8 & 40 & 15 & 20 & 18.0 & 26.4 & 1.5 & 2.25 \\
\hline 9 & 50 & 18 & 22 & 15.5 & 24.9 & 1.26 & 2.72 \\
\hline 10 & 54 & 20 & 22 & 15.6 & 17.0 & 1.5 & 1.7 \\
\hline 11 & 44 & 17 & 27 & 20.2 & 28.2 & 1.5 & 2.2 \\
\hline 12 & 49 & 20 & 28 & 19.0 & 28.7 & 2.0 & 3.8 \\
\hline 13 & 47 & 19 & 29 & 11.3 & 23.8 & 2.0 & 4.0 \\
\hline 14 & 42 & 16 & 32 & 16.6 & 24.1 & 1.5 & 2.4 \\
\hline 15 & 45 & 20 & 32 & 20.0 & 30.8 & 1.9 & 3.6 \\
\hline 16 & 46 & 19 & 35 & 21.5 & 30.0 & 2.0 & 3.0 \\
\hline 17 & 46 & 18 & 41 & 23.9 & 30.4 & 2.4 & 3.4 \\
\hline $18^{* *}$ & 58 & 17 & 58 & 28.7 & 51.8 & 2.4 & 4.6 \\
\hline
\end{tabular}

The values of breath-hold times are increasing order 


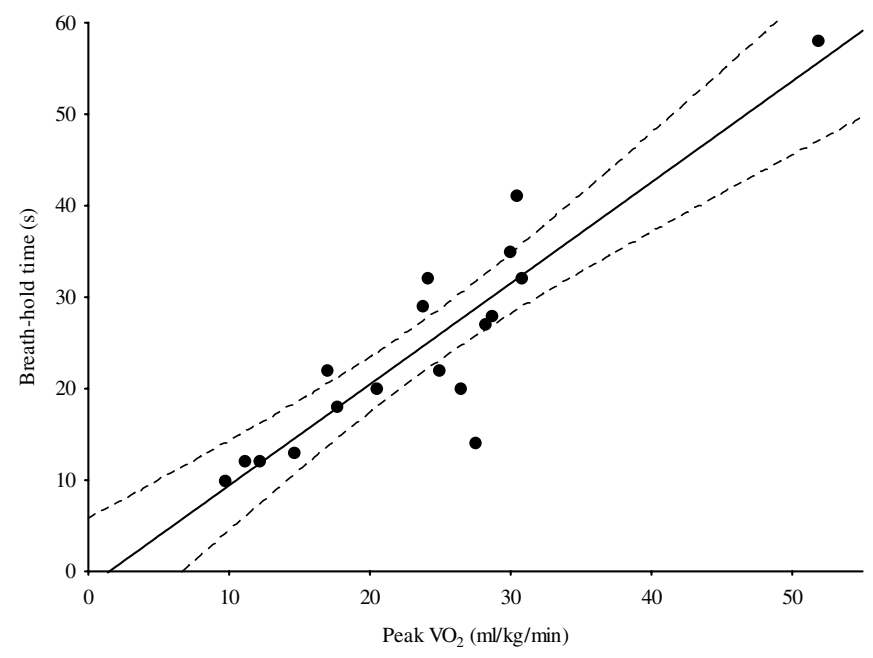

Fig. 2 Correlation between the peak oxygen uptake (peak $V \mathrm{O}_{2}$ ) and BHT $(r=0.899)$

indicating that the older patients have more serious state of the illness.

The shortest BHT (10 s) was that of a 23-year-old woman in an advanced stage (Table $1^{*}$ ). She reached the AT with a $V \mathrm{O}_{2}$ of $7.3 \mathrm{ml} / \mathrm{kg} / \mathrm{min}$ and a WC of 0.8 watt/ $\mathrm{kg}$, i.e., just sufficient for self-care. The other extreme data were those of a 17 -year-old man in a very good condition and with a normal lung function (Table $1^{* *}$ ). His BHT was $58 \mathrm{~s}$, which is normal (14). He reached the AT with a $V \mathrm{O}_{2}$ of $1,696 \mathrm{ml} / \mathrm{min}(28.7 \mathrm{ml} / \mathrm{kg} / \mathrm{min})$ a WC of 146 watt $(2.4$ watt $/ \mathrm{kg})$ and a $V_{E}$ of $59 \mathrm{l} / \mathrm{min}$. His endurance performance is well demonstrated by his data at peak exercise $\left(V \mathrm{O}_{2}=3,056 \mathrm{ml} / \mathrm{min}, V_{E}=1221\right.$ and $\mathrm{WC}=272$ watt) which are close to twice of that at AT; thus all of his data were in the normal ranges.

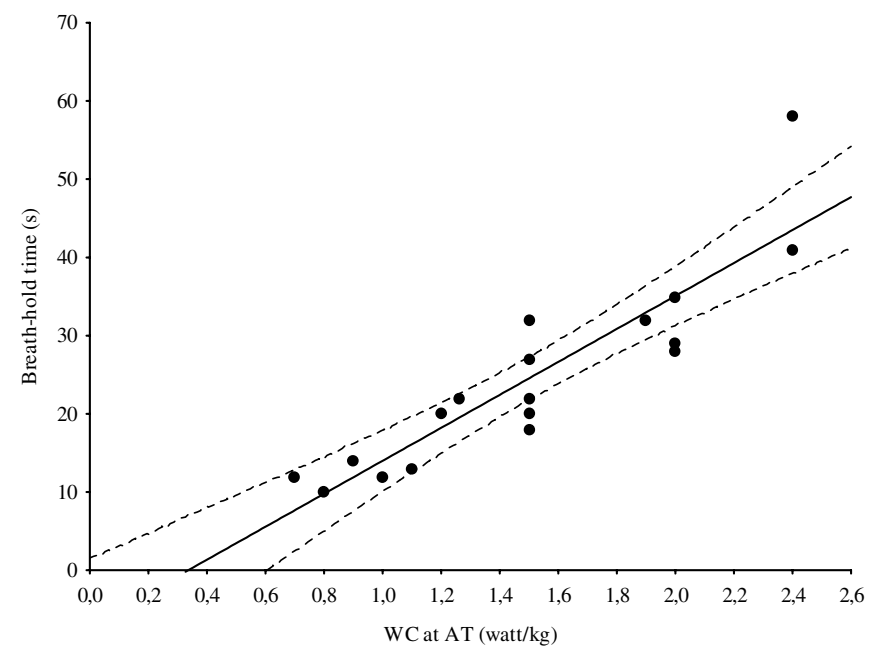

Fig. 3 Correlation between the working capacity (WC) at anaerobic threshold (AT) and breath-hold time (BHT) $(r=0.895)$

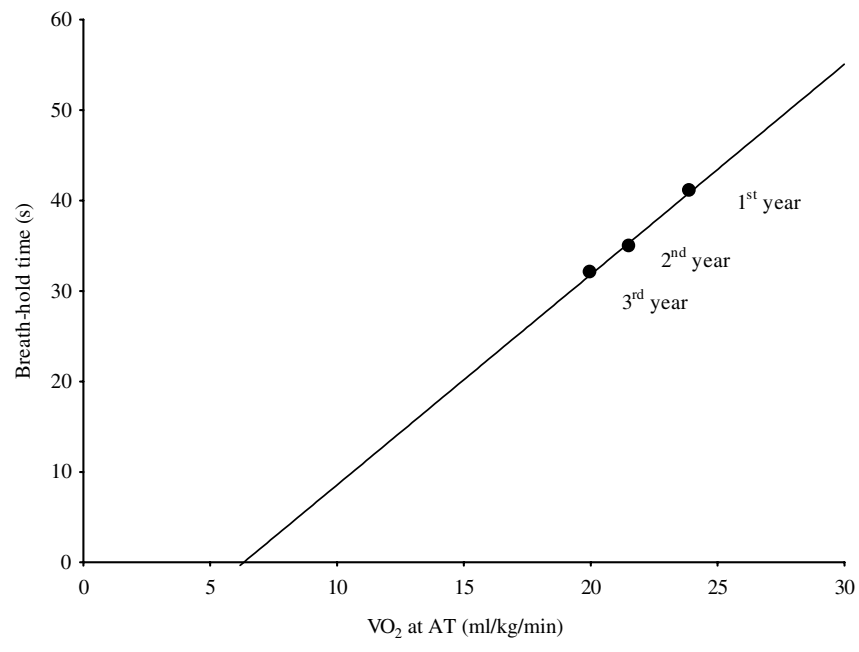

Fig. 4 Correlation between the BHT and $\mathrm{VO}_{2}$ at $\mathrm{AT}$ in the same patient during three consecutive years. The data reflect the progression of this patient's status

Correlation analysis revealed a significant positive linear correlation between the BHT and $V \mathrm{O}_{2}$ at the AT (Fig.1), with a correlation coefficient $r=0.898$. Figure 2 shows the correlation between the BHT and the peak $V \mathrm{O}_{2}$ with a correlation coefficient $r=0.895$. A very close correlation was also found between the BHT and WC at the AT (Fig. 3) with $r=0.899$. The correlation between the BHT and peakWC was slightly weaker $(r=0.82$, data not shown). All correlation coefficients were statistically significant at a level of 0.001 .

The regression equations for the relationships were:

$V \mathrm{O}_{2}$ at the $\mathrm{AT}=5.53+0.42 \times \mathrm{BHT}$

$\mathrm{WC}$ at the $\mathrm{AT}=0.56+0.38 \times \mathrm{BHT}$

According to these equations, an estimate of $V \mathrm{O}_{2}$ and $\mathrm{WC}$ at the AT can be calculated from the BHT.

One patient was followed for 3 years. Her data revealed a continuous decrease of $V \mathrm{O}_{2}$ at the AT, with a shortened BHT year by year (Fig. 4). These data reflect the slow progression in the clinical condition of the patient.

\section{Discussion}

The prognosis for patients with $\mathrm{CF}$ has improved dramatically over the past few decades, and the impressive increase in the life expectancy of individuals with CF is undoubtedly related to the recent advances in medical care. However, the benefits of the improvements in the life style and physical activity of the subjects with $\mathrm{CF}$ must not be neglected. CF patients enjoy exercises and prefer it to most other therapeutic options. Blau et al. (2002) suggested that intensive summer camp improved exercise tolerance in CF patients, and exercise has positive effects on mucus clearance, endurance, fatigue. 
These positive effects result in an overall sense of well being that in turn induces a more active, healthy life style. Exercise does not change the specific pulmonary parameters (e.g., $\mathrm{FEV}_{1}$ ) directly, but it does improve the aerobic capacity, activity levels and quality of life (Law et al. 2001; Meyers et al. 2002). Besides the clearing of airway secretions, another important task of physiotherapy is to provide a proper training program to improve the patient's fitness (Blau et al. 2002). The AT is a breaking point in the energy production. Below this point, the energy is provided mainly by the aerobic metabolism for physical activity. When the workload is too high, $V \mathrm{O}_{2}$ is not enough for the aerobic energy production to supply the muscles and the anaerobic metabolism becomes dominant. Lactic acid production increases, and the blood $\mathrm{pH}$ decreases. Healthy subjects can tolerate this change well, and after exercise their metabolism returns to a normal level within a short time. They can eliminate the overproduced $\mathrm{CO}_{2}$ by increased expiration. Since the ability of CF patients to raise their ventilation is limited, they cannot exhale the extra $\mathrm{CO}_{2}$ from the compensation of metabolic acidity. Moreover, patients with chronic lung diseases may have a compensated respiratory acidity. Therefore, during very high level of physical activity they can enter a state of complex acidity. The goals of training are to increase $V \mathrm{O}_{2}$ and endurance without inducing metabolic acidity. Therefore, the best results are produced with a workload close to the anaerobic threshold, but within the aerobic range of metabolism. For all of the above reasons, exercise testing is commonly performed in patients with $\mathrm{CF}$. Exercise testing may provide information about prognosis and functional status, may screen for exertionrelated oxyhemoglobin desaturation, and may be used to write an initial exercise prescription for those patients entering an exercise program. The current guidelines for interpretation of exercise tests, however, necessitate that the patient achieve or approach maximal exercise capacity, which is a very exhausting procedure. Exercise testing is a diagnostic modality, and the AT and the maximal exercise tolerance are important indicators of the ability to exercise. Many studies have set out to determine the pulse at the AT by a simple method, instead of applying complicated instrumental measurements, since the heart rate exhibits a significant correlation with $V \mathrm{O}_{2}$ (Schmidt and Thews 1989). The simplest method is calculation of the heart rate at the AT from the maximal heart rate in the knowledge of the age, though it does not take into account the condition of the patients. The Borg (1982) perceived rating exertion scale could be used in everyday practice to determine the physical performance based on a subjective scale of workload. However, like other visual analog scales, it is very subjective. Maximal cardiopulmonary testing has increased in practice and importance in the CF population in recent years. It may be used to evaluate functional capacity, to assess for oxyhemoglobin desaturation, to guide exercise prescription for subjects entering and exercise/rehabilitation program, and to assess outcomes to therapeutic interventions or clinical trials. In addition, maximal exercise capacity has been shown to be one of the best markers of prognosis and mortality in CF patients by Nixon et al. (1992).

A number of studies have investigated the BHT in healthy populations, and especially in divers. The reported values of the BHT differed significantly between the studies, e.g. Lin et al. (1974) observed $162 \pm 13$ s, but others, Whitelaw et al. (1981) and Cain (1957) considerably shorter times (61.6-89.5 s). Our results are within the range measured by Gay et al. (1994) in patients with chronic obstructive pulmonary disease. Various factors influence the BHT. Lin et al. (1974) found that the BHT was significantly increased after oxygen inspiration and decreased during exercise, showing a correlation with the reciprocal of $V \mathrm{O}_{2}$. Furthermore, several parameters would change during the BHT. Thus, the blood lactate level increased above $3.5 \mathrm{mmol} / \mathrm{l}$ at the BHT in untrained subjects (Delapille et al. 2002). Similarly, a high blood lactate $(>4 \mathrm{mmol} / \mathrm{l})$, a low alveolar $\mathrm{O}_{2}$ pressure $(<30 \mathrm{mmHg})$, and a high alveolar $\mathrm{CO}_{2}$ pressure $(>50 \mathrm{mmHg}$ ) were registered at the breath-hold breaking in extreme divers by Ferretti (2001). Ward et al. (2001) demonstrated that a dyspnoeic sensation has an important role in the length of the BHT during dynamic exercise. They found an exponentially increasing dyspnoeic sensation at a progressively increasing work rate. Hurewitz and Sampson (1987) found that the alveolar partial pressure of $\mathrm{O}_{2}$ decreased to $70 \mathrm{mmHg}$ in the obese after breath-hold of only $15 \mathrm{~s}$ while this degree of hypoxia did not occur in nonobese subjects until the breath-hold was sustained for $30 \mathrm{~s}$. Therefore, since dyspnoea is likely to be dominant exercise limiting factor in CF consequent to impaired lung function it may explain the correlation in CF patient. Of course, we do not exclude that simple lung function test would not provide a suitable index of aerobic capacity in $\mathrm{CF}$ patients, as it was suggested by several authors (Klijn et al. 2004; Frangolias et al. 2003). However, Turchetta et al. (2004) suggested that $\mathrm{FEV}_{1}$ did not reflect the improvement in endurance capacity and peak $V \mathrm{O}_{2}$ in $\mathrm{CF}$ patient.

Since our results have revealed a significant correlation between the BHT and the $V \mathrm{O}_{2}$ and $\mathrm{WC}$ at the AT and peak $V \mathrm{O}_{2}$, these data suggest that simple BHT determination might be a reliable method for the prediction of the exercise tolerance in these patients. The BHT values in our patients are in general agreement with the findings of Gay et al. (1994), who measured a BHT of 18-32 s (mean: $25 \mathrm{~s}$ ) in subjects who were heavy smokers or had chronic obstructive pulmonary disease or congestive heart failure. However, they did not measure the physical performance of their patients. Our data as well as the data of Gay et al. (1994) suggest that the BHT reflects the defective gas exchange. The best BHT does not contradict this fact, as it was that of an almost healthy young patient. The highest BHT (58 s) among our data is equivalent to the mean BHT 
measured by Fowler (1959) $52.2 \mathrm{~s}$ on healthy adult subjects after breathing room air held at inspiratory level. However, they did not determine the WC of these subjects.

\section{Conclusions}

The above results suggest that the voluntary BHT serves as a useful index for the exercise tolerance of $\mathrm{CF}$ patients. This parameter could be obtained in a noninvasive manner, and indicates changes in the cardiopulmonary function. It is, therefore, suitable for determination of the level of physical training. From the knowledge of BHT, the probable $V \mathrm{O}_{2}$ and $\mathrm{WC}$ at the AT and the peak $V \mathrm{O}_{2}$ can be calculated. All of these data are useful in the planning of the physical training program of the patients.

We have demonstrated that the noninvasive BHT can be used to obtain an unbiased estimate of the aerobic fitness. In the daily routine BHT can substitute the spiro-ergometric test and other sophisticated experimental measurements. Obviously, the noninvasive nature of the BHT permits repeated testing to be carried out easily and conveniently. Reexamining the BHT could show the efficiency of training and may reflect the cardiopulmonary status of the patients as well. The utility of noninvasive, simple measurement, as performed in this study, should make application of BHT safer and more widely available. This study showed that the BHT correlates very well with the commonly used measures of respiratory function in these patients. Further studies in healthy persons and in patients with different pulmonary diseases are needed to address the observation of aerobic capacity in relation to $\mathrm{BHT}$.

\section{References}

Baldwin DR, Hill AL, Peckham DG, Knox AJ (1994) Effect of addition of exercise to chest physiotherapy on sputum expectoration and lung function in adults with cystic fibrosis. Respir Med 88:49-53

Blau H, Mussaffi-Georgy H, Fink G, Kaye C, Szeinberg A, Spitzer SA, Yahav J (2002) Effects of an intensive 4-week summer camp on cystic fibrosis. Chest 121:1117-1122

Borg GAV (1982) Psychophysical bases of perceived exertion. Med Sci Sports Exerc 14:378-380

Cain SM (1957) Breaking point of two breath-holds separated by a single inspiration. J Appl Physiol 11(1):87-90

Casaburi R (1993) A primer in cardiopulmonary exercise testing. Monaldi Arch Chest Dis 48:266-271

Courteix D, Bedu M, Fellmann N, Heraud MC, Coudert J (1993) Chemical and nonchemical stimuli during breath-holding in divers are not independent. American Phyisological Society 2022-2027

Delapille P, Verin E, Tourny-Chollet C, Pasguis P (2001) Breath-holding time: effects of non chemical factors in divers, and non-divers. Eur J Physiol 442(4):588-594
Delapille P, Verin E, Tourny-Chollet C (2002) Ventilatory adaptations for breath-holding in divers. Rev Mal Respir 19(2):217-228

Dickstein K, Barvik S, Aarsland T, Snapinn S, Karlsson J (1990) A comparison of methodologies in detection of the anaerobic threshold. Circulation Jan 81(1 Suppl):1138-1146

Dickstein K, Aarsland T, Svanes H, Barvik S (1993) A respiratory exchange Ratio to 1 provides a reproducible index of submaximal cardiopulmonary exercise performance. Am J Cardiol 71 June 1:1367-1369

Ferretti G (2001) Extreme human breath-hold diving. Eur J Appl Physiol 84(4):254-271

Fowler WS (1954) Breaking point of breath-holding. J Appl Physiol 6:539-545

Frangolias DD, Holloway CL, Vedal S, Wilxon PG (2003) Role of exercise and lung function in predicting work status in cystic fibrosis. Am Respir Crit Care Med 167:150-157

Freeman W, Stableforth DE, Cayton RM, Morhan MD (1993) Endurance exercise capacity in adults with cystic fibrosis. Respir Med 87(7):541-549

Gay SB, Sistrom CL, Holder CA, Suratt PM (1994) Breath-holding capability of adults. Implication for spiral CT fast-aquisition MRI and angiography. Invest radiol 29(9):848-851

Gibson RL, Burns JL, Ramsey BW (2003) Pathophysiology and management of pulmonary infections in cystic fibrosis. Am J Respir crit Care Med 168:918-951

Godfrey S, Campbell EJ M (1986) The control of breath-holding. Respir Physiol 5:385-400

Hurewitz AN, Sampson MG (1987) Voluntary breath-holding in the obese. J Appl Physiol 62:2371-2376

Klijn P, Oudshoorn A, Ent C, Net J, Kimpen J, Helders P (2004) Chest 125/4 April:1299-1305

Law C, Burton Keith J (2001) Do patient with cystic fibrosis need to exercise? Sport Exercise Winter CJ

Lin YC, Lally DA, Moore TO, Hong SK (1974) Physiological and conventional breath-hold breaking points. J Appl Physiol 37(3):291-296

Meyers N, Mellis CM, Cooper PJ, Van Asperen PP (2002) Randomized controlled study of in-hospital exercise training programs in children with cystic fibrosis. Pediatr Pulmonol 33(3): 194-200

Nixon PA, Orenstein DM, Kelsey SF, Doershuk CF (1992) The prognostic value of exercise testing in patients with cystic fibrosis. N Engl J Med 327:1785-1788

O’Neill PA, Dodds M, Phillips B, Poole J, Webb AK (1987) Regular exercise and reduction of breathlessness in patients with cystic fibrosis. Br J Dis Chest 81:62-69

Perez - Padilla R, Cervantes D, Chapela R, Selman M (1989) Rating of breathlessness at rest during acute asthma: correlation with spirometry and usefulness of breath-holding time. Rev Invest Clin 41:209-213

Prasad SA, Cerny FJ (2002) Factors that influence adherence to exercise and their effectiveness: application to cystic fibrosis. Pediatr Pulmonol 34:66-72

Schmidt RF, Thews G (1989) Human physiology. Springer, Berlin Heidelberg New York

Selvadurai HC, Blimkie CJ, Meyers N, Mellis CM, Cooper PJ, Van Asperen PP (2002) Randomized controlled study of in-hospital exercise training programs in children with cystic fibrosis. Pediatr Pulmonol 33(3):194-200

Stroud RC (1959) Combined ventilatory and breath-holding evaluation of sensitivity to respiratory gases. J Appl Physiol 14(3):353-356

Taskar V, Clayton N, Atkins M, Shaheen Z, Stone P, Woodcock A (1995) Breath-holding time in normal subjects, snorers, and sleep apnea patients. Chest 107:959-962

Turcheta A, Salerno T, Lucidi V, Libera F, Cutrera R, Bush A (2004) Usefulness of a program of hospital-supervised physical training in patients with cystic fibrosis. Ped Pulmon 38:115-118

Ward SA, Macias D, Whipp BJ (2001) Is breath-hold time an objective index of exertional dyspnoea in humans? Eur J Appl Physiol 85(3-4):272-279 
Whitelaw WA, McBride B, Amar J, Corbet K (1981) Respiratory neuromuscular output during breath-holding. J Appl Physiol 50(2):435-443
Wisen AGM, Wohlfart B (2004) Aerobic and functional capacity in a group of healthy women: reference values and repeatability. Clin Physiol Funct Imaging 24 6:341-351 